\title{
URBAN BOUNDARY EXTRACTION AND URBAN SPRAWL MEASUREMENT USING HIGH-RESOLUTION REMOTE SENSING IMAGES: A CASE STUDY OF CHINA'S PROVINCIAL CAPITAL
}

\author{
Hao Wang ${ }^{1, *}$, Xiaogang Ning ${ }^{1}$, Hanchao Zhang ${ }^{2}$, Yafei Liu ${ }^{1}$, Fan Yu ${ }^{1}$ \\ ${ }^{1}$ Institute of photogrammetry and remote sensing, Chinese Academy of Surveying and Mapping, Beijing, China - (wanghao, \\ ningxg)@casm.ac.cn; 1369521239@qq.com; yufan021@126.com \\ ${ }^{2}$ State Key Laboratory of Information Engineering in Surveying, Mapping and Remote Sensing, Wuhan University, Wuhan, \\ China-1172670795@qq.com
}

Commission III, WG III/7

KEY WORDS: Urban boundary, Urban sprawl, High-resolusion remote sensing image, Provincial capitals

\begin{abstract}
:
Urban boundary is an important indicator for urban sprawl analysis. However, methods of urban boundary extraction were inconsistent, and construction land or urban impervious surfaces was usually used to represent urban areas with coarse-resolution images, resulting in lower precision and incomparable urban boundary products. To solve above problems, a semi-automatic method of urban boundary extraction was proposed by using high-resolution image and geographic information data. Urban landscape and form characteristics, geographical knowledge were combined to generate a series of standardized rules for urban boundary extraction. Urban boundaries of China's 31 provincial capitals in year 2000, 2005, 2010 and 2015 were extracted with above-mentioned method. Compared with other two open urban boundary products, accuracy of urban boundary in this study was the highest. Urban boundary, together with other thematic data, were integrated to measure and analyse urban sprawl. Results showed that China's provincial capitals had undergone a rapid urbanization from year 2000 to 2015, with the area change from 6520 square kilometres to 12398 square kilometres. Urban area of provincial capital had a remarkable region difference and a high degree of concentration. Urban land became more intensive in general. Urban sprawl rate showed inharmonious with population growth rate. About sixty percent of the new urban areas came from cultivated land. The paper provided a consistent method of urban boundary extraction and urban sprawl measurement using high-resolution remote sensing images. The result of urban sprawl of China's provincial capital provided valuable urbanization information for government and public.
\end{abstract}

\section{INTRODUCTION}

With the development of urbanization, more and more population reside in cities. Along with the rapid growth of urban populations comes rapid urban sprawl. Especially since 2000, China's urbanization development has entered a new stage. Although urbanization improves socioeconomic development and life quality, urbanization issues, such as blind expansion, faster land urbanization than population urbanization, extensive and inefficient use of construction land, unreasonable urban spatial morphology and structure, insufficient resource and environmental carrying capacity, become more and more serious, which results in enormous ecological and environmental challenges, such as heat island effect(Yuan and Bauer, 2007), local climate change(Stone et al., 2010), arable land loss(Tan et al., 2005), and water pollution(Yin et al., 2005).

Urbanization can be measured from the urbanization of "population" and the urbanization of "land". The urbanization of "population" can be represented by urbanization rate (ratio of urban population to total population), and the urbanization of "land" can be represented by non-agricultural urban area(Li et al., 2012). Compared with the incomprehensible indicator of population transfer resulting from the urbanization of population, the urbanization of "land", which is the expansion of urban area, is a direct result of urbanization acting on geographical space(Che et al., 2011). Remote sensing technology has the advantages of being realistic, objective, strong and low cost, and has become an important technical measure for monitoring the urbanization of "land"(Hu et al., 2006; Mu et al., 2007). However, there are many concepts related to "urban areas" or "urban boundary", which have different starting points and characteristics(Bagan H, 2012; Duan and Huang, 2008; P.R.C, 1999; Schneider et al., 2010; Wang and Liu, 2013; Weicheng, 2002; Xu and Gao, 2016). Many researchers regarded construction land or impervious surface, which is one class of land-use types, as urban areas $(\mathrm{Li}$ et al., 2017; Li et al., 2015; Zhang et al., 2016). Some other researchers considered definition of urban areas from the aspect of the function of urban land(Schneider and Woodcock, 2008). There are many image sources for urbanization monitoring(Griffiths and Hostert, 2010). In the early days, MODIS was the mainly data source in urbanization monitoring(Bartholome and Belward, 2005; Costa et al., 2016; Friedl et al., 2002; Wan et al., 2015). Afterwards, the medium resolution satellite images based on the Landsat series(Angiuli and Trianni, 2013; Bagan and Yamagata, 2012; Gao et al., 2012; Guindon et al., 2004; Son and Chen, 2012; Sun et al., 2017; Wang et al., 2012) were used. With the increasing number of high-resolution satellites, many researchers used high-resolution images for automatic extraction of urban

* Corresponding author 
areas(Chao et al., 2010; Chen et al., 2013; Lin and Ning, 2017; Ni et al., 2017; Ning and Lin, 2017). But they are mainly used in urban scale due to the limited applicability of automated extraction methods.

The above-mentioned studies provided abundant methods for understanding the spatio-temporal sprawl process of urbanization in China, but there are still some deficiencies. Firstly, the methods and the standards of urban boundary extraction were inconsistent, leading to differences in results. So, it was difficult to carry out accuracy verification and comparative analysis among many cities. Secondly, the results were mostly based on MODIS and Landsat series of satellite images. The lower image resolution resulted in poorer accuracy of the extraction results.

In this paper, a semi-automated extraction method of urban boundary with computer automatic recognition and manual interpretation was proposed. Urban boundaries of China's 31 provincial capitals in year 2000,2005, 2010 and 2015 were extracted by using high-resolution images under the unified standard. Then urban boundary result was compared with other urban boundary products to assess the accuracy. At last, urban area was used as the representation of "land" urbanization to carry out the urban spatio-temporal sprawl analysis.

\section{MATERIALS AND METHODS}

\subsection{Study Area}

China's 31 provincial capitals, which do not include Hong Kong, Macao and Taiwan, have been selected as study area. According to the economic division, they are divided into East China, Central China, West China and Northeast China. The provincial city is the political center of the provincial administrative unit, as well as the economic center and cultural center. Urbanization of provincial capitals basically represents the highest level of the province's urbanization. In the early twenty-first Century, urban economy and society of provincial capitals developed rapidly, and the urban boundary expanded rapidly, which made provincial capitals very representative in the urbanization analysis in China.

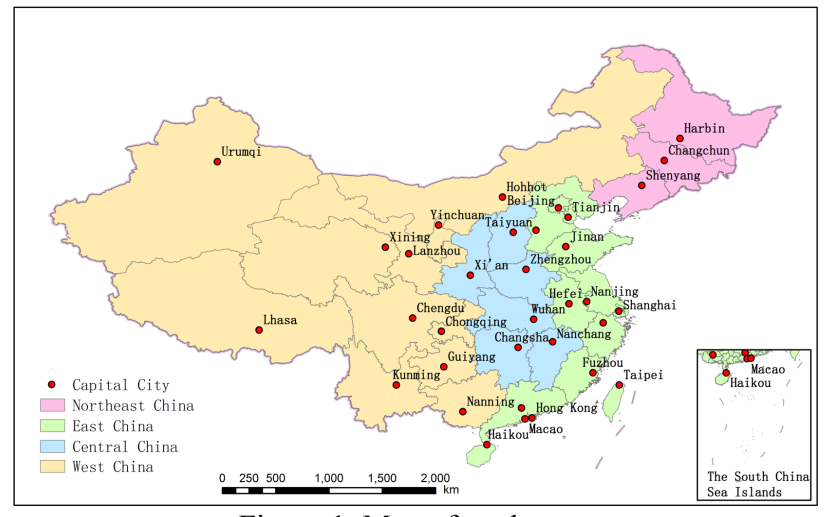

Figure 1. Map of study area

\subsection{Data Preparation}

High-resolution remote sensing images, population and GDP data, land use data, and China's first national geoinformation survey data were collected for urban boundary extraction and urban sprawl analysis. Remote sensing images, which mainly have the resolution better than 2 meters, were obtained from the surveying and Mapping Department. Images were geometrically corrected and projected onto the CGCS2000 coordinate system. Population and GDP data came from the Chinese urban statistical yearbook. Land use data of year 2000 came from the resources and environmental science data center of the Chinese Academy of Sciences. The land use data were merged into five categories, which were cultivated land, construction land, forest and grassland, water area, and unused land. China's first national geoinformation survey data, which include land cover, urban road data, geographical name and address data, township-level and county-level administrative divisions, provided an important reference for urban boundary extraction. All thematic data were spatially matched with remote sensing images.

\subsection{Urban Boundary Extraction}

Urban boundary was extracted by combining computer automatic extraction with manual visual interpretation (Figure 2 ). High-resolution remote sensing images were automatically extracted to obtain residential areas by fusing the right angle and right edge features(Lin and Ning, 2017; Ning and Lin, 2017). Locations of district governments were overlaid on the residential areas. The contiguous residential regions, which district governments laid on, were selected as the initial urban boundary. Initial urban boundary was edited and revised by manual visual interpretation according to a series of principles and rules to obtain the final urban boundary. Final urban areas include both central urban area and enclave urban area. The principles and rules are as follows.

1) Principle of the limitation of administrative division. Urban areas must be located in the scope of urban administrative division, and cannot exceed administrative division boundary.

2) Principle of the drawing of urban boundary outline. Urban boundary line was preferentially drawn along the boundary of linear objects, such as roads, rivers and walls. It cannot cross the buildings and structures. Cultivated land is not allowed inside the urban boundary. When urban boundary lays at riverbank, urban boundary outline is drawn along the high water level line of the river if riverbank appears urban greening landscape. Otherwise urban boundary line is sketched along the roads nearby the riverbank. Urban boundary is preferentially sketched along the border of complete block, which has obvious boundary, such as courtyards or fences. If block boundary is not obvious or the proportion of unconstructed area in the whole block is high, urban boundary is sketched along the actual boundary of the constructed land.

3) Principle of the decision of central centralized and contiguous region. The central centralized and contiguous region, which is named as central urban areas, is connected to district government through the road, and the border of the region extends towards outside until the distance of constructed land to central urban areas is more than 50 meters.

4) Principle of the judgment of urban landscape. Fringe of urban areas must have one of the following landscape characteristics, including urban housing construction region, urban road, urban green space, urban square, parking lot, stadiums(Gong and Howarth, 1992a; Gong and Howarth, $1992 b)$. Block, which is surrounded by the streets, is the most important urban landscape characteristic. 
5) Principle of the judgment of enclave urban areas. Enclave urban area is an important part of urban areas, but it is not belonged to the central centralized and contiguous region. It has the following characteristics. Firstly, it is connected to the centralized and contiguous region by main road, and the distance from its border to the border of the centralized and contiguous region is more than 50 meters. Secondly, it has the characteristics of urban landscape. Thirdly, enclave urban area, area of which must be more than 60 hectares, is a centralized and contiguous region where one of the following units lay. The units include street office, city administration, industrial and mining area, development zone, research unit, college and other special areas.

6) Principle of inverse extraction of urban boundary from new time to old time. Firstly, urban boundary of the latest phase was extracted. Then change detection technology was used to find urban boundary change of previous phase. At last, previous urban boundary was obtained by integrating the latest urban boundary with the change information between two phases. This principle guarantees the proper and consistent topological of among multi- period urban boundaries.

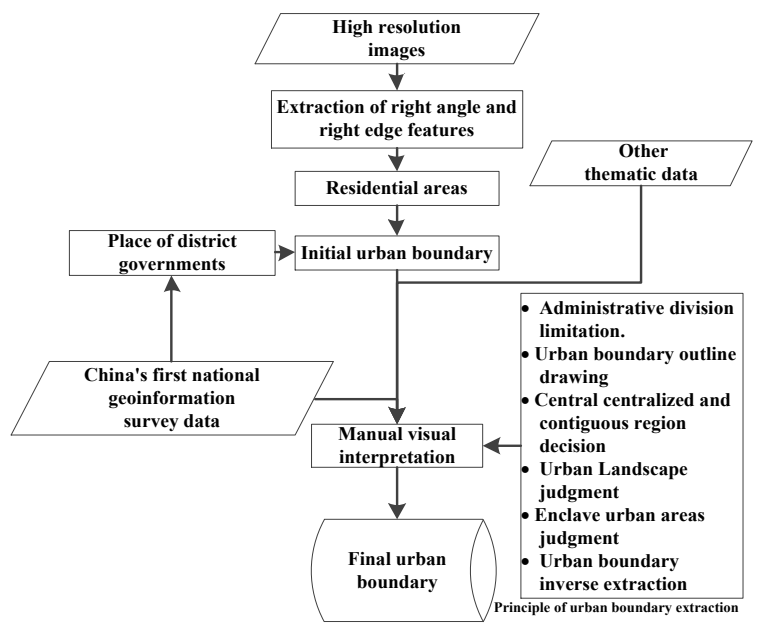

Figure 2. The workflow of urban boundary extraction

\subsection{Urban Sprawl Analysis Indicators}

Urban sprawl speed, sprawl intensity, compactness, and urban sprawl coordination coefficient are used to analyze urban sprawl from four aspects, which are urban spatio-temporal sprawl process, urban land use efficiency change, urban sprawl coordination with population growth, and land use change in urban sprawl areas.

\section{(1) Urban sprawl speed}

Urban sprawl speed $V_{i}$ is the annual growth rate of urban area in a certain period. It can reflect the absolute difference of urban sprawl speed in different urban areas per unit time.

$$
V i=\Delta U_{i j} /\left(\Delta t_{j}\right) \times 100 \%
$$

where

$$
\Delta U_{i j}=\text { urban sprawl area of unit } i \text { in period } j
$$$$
\Delta t_{j}=\text { time span of period } j
$$

\section{(2) Urban sprawl intensity}

Urban sprawl intensity $\mathrm{N}_{\mathrm{i}}$ is the annual urban sprawl ratio of the urban areas in certain period to the urban areas in base period. It can reflect the relative difference of urban sprawl speed in different urban areas per unit time.

$$
V i=\Delta U_{i j} /\left(\Delta t_{j} \times M_{i}\right) \times 100 \%
$$

where $\Delta U_{i j}=$ urban sprawl area of unit $i$ in period $j$

$\Delta t_{j}=$ time span of period $j$

$M_{j}=$ urban area of unit $i$ in base period

\section{(3) Compactness}

Compactness BCI is an important indicator reflecting urban morphology. It can reflect the spatial concentration degree of different urban functions(Huang and Yun, 2012). There are many methods of compactness calculation, and the method proposed by Boyce is the most widely used (Boyce and Clark, 1964).

$$
B C I=2 \sqrt{\pi A} / P
$$

where $A=$ urban area

$P=$ circumference of urban boundary

(4) Urban sprawl coordination coefficient

Urban sprawl coordination coefficient $\mathrm{K}$ is the ratio of urban sprawl rate to urban population growth rate in certain period. It can reflect if they grow at a coordinate way.

$$
\begin{gathered}
K=G R / P R \times 100 \% \\
G R=\left(\sqrt[\Delta t]{A_{t} / A_{0}-1} \times 100 \%\right.
\end{gathered}
$$

where $\quad P R=$ annual average growth rate of urban population $G R=$ annual average growth rate of urban areas $A_{t}=$ urban area at the end of a certain period $A_{0}=$ urban area at the beginning of a certain period $\Delta t=$ time span of the period

\section{RESULT AND DISCUSSION}

\subsection{Urban Boundary Results Assessment}

The area of urban areas of China's 31 provincial capitals was used to compare the accuracy of urban boundary extraction between three products (Figure 3 ).

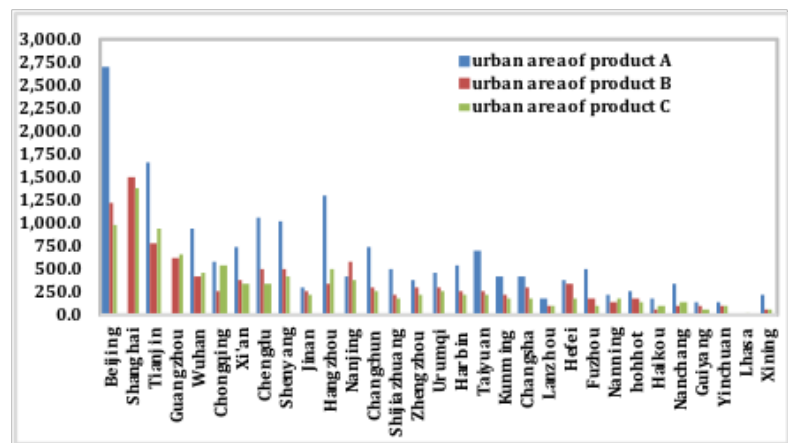

Figure 3. Comparison of urban area of China's 31 provincial capitals in year 2010 between different products

Urban boundary product A came from the report "East Asia's Changing Urban Landscape", which was published by World Bank Organization(Bank, 2015). Product A was extracted automatically by using MODIS images. Urban boundary product B came from the paper "China's urban expansion 
from 1990 to 2010 determined with satellite remote sensing"(Wang et al., 2012). Product B was extracted manually by using Landsat images. Urban boundary product of this study is marked as C. It should be pointed out that urban boundaries of Shanghai and Guangzhou in product A represented the urban boundary of the Yangtze River Delta Urban Agglomeration and Pearl River Delta Urban Agglomeration respectively, so they were not included in the comparison of urban boundary results. Besides, urban boundary of Lhasa was not given in product $\mathrm{A}$ and product $\mathrm{B}$, so Lhasa was not included in the comparison of urban boundary results.

Overall, urban area of product A is obviously larger than that of product $\mathrm{B}$ and product $\mathrm{C}$. Urban area of product $\mathrm{B}$ is slightly larger than that of product C. Average urban area of product $\mathrm{C}$ of China's 31 provincial capitals is $24.8 \%$ less than that of product B. Average urban area of product A and B of China's 31 provincial capitals is about one half of product $\mathrm{C}$. In order to analyze the specific difference between three products, Beijing was taken as the study area. From the highresolution images in Figure 4a, it can be found that urban areas in Beijing of product A contain a large number of cultivated land and woodland. Even the mountain areas were mistaken for urban areas. The reason of the poor accuracy and granularity of product $\mathrm{A}$ is due to the coarse resolution of MODIS, which made it difficult to achieve the similar accuracy with product $\mathrm{B}$ and product $\mathrm{C}$. Urban areas of product $\mathrm{B}$ have a similar spatial distribution with that of product $\mathrm{C}$, but there are still some differences. Some high-rise building aggregation areas are missing and not included in Product C (Figure 4b). Whereas low-rise buildings in ruralurban fringe areas (Figure 4c), some rural areas (Figure 4d), large area of farmland (Figure 4e) were misclassified into urban areas in product B. Figure $4 \mathrm{f}$ shows that obvious leakage of urban areas exists in Landsat image. Figure $4 \mathrm{~g}$, $4 \mathrm{~h}$ and 4I show that it is difficult to identify the specific urban boundary due to the coarser resolution of Landsat, which makes it easy to misclassify objects with similar spectra characteristics into urban areas.

It can be concluded that the accuracy of product $\mathrm{A}$ is the worst, and the accuracy of product $\mathrm{C}$ is the highest. The spatial resolution of image data source has a significant effect on the accuracy of urban boundary extraction results. High-resolution images can effectively avoid misclassification, leakage poor accuracy of urban boundary, and can also distinguish urban areas with rural-urban fringe areas and rural areas accurately.

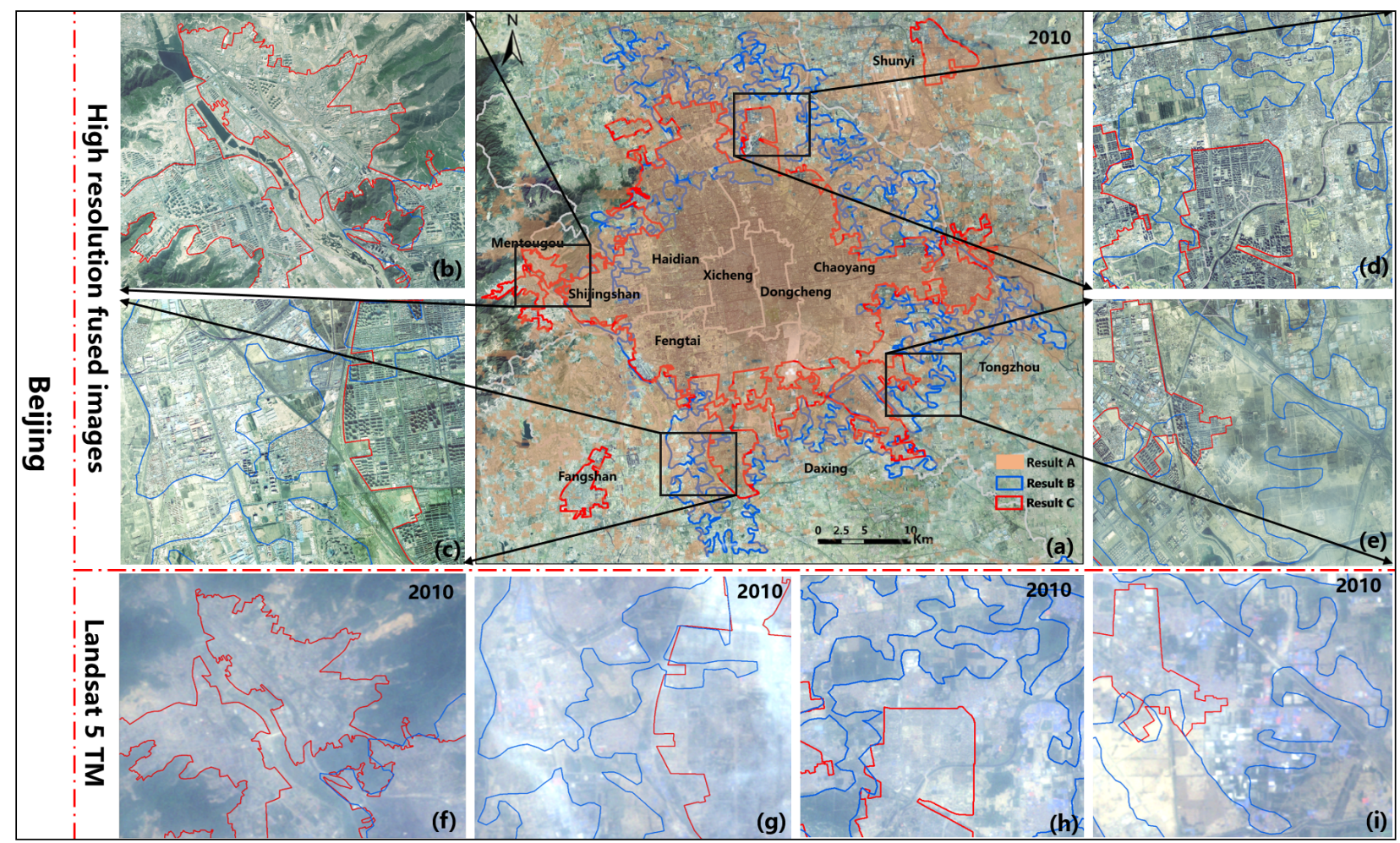

Figure 4. Comparison of Beijing urban boundaries of product A, B and C in year 2010

\subsection{Urban Spatio-temporal Sprawl Process}

In year 2000,2005, 2010 and 2015, the total urban area of China's 31 provincial capitals was $6520.2 \mathrm{~km}^{2}, 8217.7 \mathrm{~km}^{2}$, $10361.1 \mathrm{~km}^{2}$ and $12398.3 \mathrm{~km}^{2}$ respectively. From year 2000 to 2015 , the total urban area increased by $90.0 \%$, which was $5878.1 \mathrm{~km}^{2}$.

In year 2015, the total urban area of China's 31 provincial capitals accounted for $6 \%$ of the total area of 31 cities. The average urban area in East China was the highest, and the average urban area in Northwest China, Central China and
West China decreased in turn. The average urban area of China's 31 provincial capitals $\left(399.9 \mathrm{~km}^{2}\right)$ was far higher than the median $\left(267.0 \mathrm{~km}^{2}\right)$, indicating that urban area was mainly concentrated in a few cities. Urban area of the top ten provincial capitals, which were mainly composed of first tier cities, accounted for $63.4 \%$ of the total area of 31 cities. Urban area of Beijing, Shanghai, Tianjin and Guangzhou was one third of the total area of 31 cities. Urban area of the last ten provincial capitals only accounted for $10.9 \%$ of the total area of 31 cities. The last ten provincial capitals include 6 cities in West China, 2 cities in Central China, and 2 cities in East China. 
From year 2000 to 2015, the average sprawl speed of China's 31 provincial capitals was $12.6 \mathrm{~km}^{2}$ per year. Provincial capitals in East China had the fastest average sprawl speed, which was $17.7 \mathrm{~km}^{2}$ per year. Provincial capitals in Central China had the slowest average sprawl speed, which was 8.1 $\mathrm{km}^{2}$ per year. Urban sprawl area of the top ten provincial capitals accounted for $65.6 \%$ of the total sprawl area of 31 cities. Urban sprawl area of the last ten provincial capitals only accounted for $10.4 \%$ of the total sprawl area of 31 cities. The top ten cities with biggest urban area were basically the same as those with biggest urban sprawl area. The last ten cities with smallest urban area were basically the same as those with smallest urban sprawl area. It indicates that the bigger urban area is, the bigger urban sprawl area will be. And the smaller urban area is, the smaller urban sprawl area will be. So it can be concluded that China's urban sprawl has the characteristics of centralization.

From year 2000 to 2015, urban sprawl intensity of 24 provincial capitals in China was over $50 \%$, and that of 12 provincial capitals was more than $100 \%$. With the higher urban sprawl intensity in West China, Northeast China and Central China than that in East China, relative difference of urban area in different regions decreased. The difference of urban area between West China and East China decreased the most significantly. Ratio of the average urban area in East China to that in West China decreased from $300 \%$ to $220 \%$.

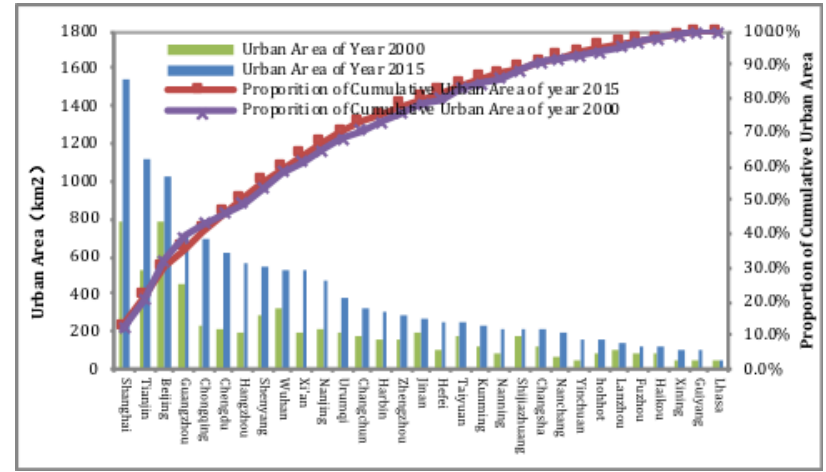

Figure 5. Urban area and the change from year 2000 to 2015

\subsection{Urban Land Efficiency Change}

From year 2000 to 2015, the average GDP per urban area of China's 31 provincial capitals increased exponentially in general. In year 2000, East China, Northeast China, Central China and West China were ranked from high to low according to average GDP per urban area. Average GDP per urban area showed a gradual decline from east to west. The differences of average GDP per urban area were relatively small in different regions. From year 2000 to 2015, the average GDP per urban area in different regions showed an inhomogeneous great increase. Annual growth rate of the average GDP per urban area in Northeast China was only 9.4\%, which was lower than that in East China, Central China and West China. As a result, the average GDP per urban area in Northeast China ranked from second to last. In year 2015, East China, Central China, West China and Northeast China were ranked from high to low according to average GDP per urban area. In year 2015, provincial capitals of the top ten average GDP per urban area included 6 cities in East China, 2 cities in Central China and 2 cities in West China. In year
2015, provincial capitals of the last ten average GDP per urban area included 6 cities in West China, 2 cities in Northeast China, 1 city in Central China and 1 city in East China. It showed that provincial capitals with high degree of intensive land per urban areas distributed widely. Whereas, provincial capitals with low degree of intensive land per urban areas basically distributed in West China and Northeast China.

The Compactness of China's 31 provincial capitals appeared regional different. Average compactness of provincial capitals in Central China was the highest, and compactness of provincial capitals in West China was the lowest. From year 2000 to 2015, the dispersion degree of compactness of China's 31 provincial capitals decreased, which indicated that difference between provincial capitals reduced slightly. Compactness of 27 provincial capitals increased. It indicated that the provincial capitals became more compact and intensive from the spatial form. The result can also be founded from the morphology change of urban boundary that urban sprawl type was mainly internal filling.

\subsection{Urban sprawl coordination}

From year 2000 to 2015, urban sprawl rate and urban population growth rate of China's 31 provincial capitals were not coordinated with each other generally. Urban sprawl rate of 14 provincial capitals lagged behind urban population growth rate. These cities included 7 cities in East China, which is $70 \%$ of the total number of provincial capitals in East China, 5 cities in West China and 2 cities in Central China. It indicated that provincial capitals in East China lagged behind urban population growth rate generally. It should be pointed out that Beijing and Shanghai had a different sprawl mode with other provincial capitals in East China. Urban sprawl rate of 14 provincial capitals was ahead of urban population growth rate. These cities included 2 cities in East China, 5 cities in West China, 4 cities in Central China, which is $70 \%$ of the total number of provincial capitals in East China, and 3 cities in Northeast China, which is $100 \%$ of the total number of provincial capitals in Northeast China. It indicated that provincial capitals in Northeast China and Central China were ahead of urban population growth rate generally. Only 3 provincial capitals, which were Chongqing, Chengdu and Fuzhou, showed a relative coordinated urban sprawl.

\subsection{Land Use Change in Urban Sprawl Areas}

From year 2000 to 2015, the area of cultivated land occupied by urban sprawl areas of China's 31 provincial capitals is $60.6 \%$ of the total urban sprawl area, which made cultivated land the major source of urban sprawl areas. Construction land, which occupied $27.1 \%$ of the total urban sprawl area, was the second major source of urban sprawl areas. Except for Xining and Haikou, urban sprawl areas of the other 29 provincial capitals mainly came from cultivated land. The area of cultivated land occupied in the process of urban sprawl was slightly more than that of construction land, which indicated that both cultivate land and construction land were the important source of urban sprawl areas. Nanjing, Lanzhou and Xining had the similar urban sprawl mode with Beijing. The area of cultivated land occupied in the process of urban sprawl was slightly more than that of forest and grassland, which indicated that cultivate land, forest and grassland were the important source of urban sprawl areas. Construction land, forest and grassland, cultivated land occupied the similar proportion of the total urban sprawl areas of Haikou, which 
indicated that construction land, forest and grassland, cultivate land were the important source of urban sprawl areas.

\section{CONCLUSION}

In this study, a semi-automated method of urban boundary extraction with computer automatic recognition and manual interpretation by using high-resolution images was proposed. A series of standard rules and processes was proposed to guarantee the consistent and comparative result of urban boundary. With this method, a set of consistent and highprecision urban boundaries of China's provincial capitals in year 2000, 2005, 2010, 2015 were obtained. Compared with other urban boundary product, the product in this study has the highest accuracy.

Based on the urban boundary and other reference data, urban sprawl was measured with urban sprawl analysis indicators. The results can be concluded as follows. 1) In year 2015, the total urban area of China's provincial capitals was $12398.3 \mathrm{~km}^{2}$. From year 2000 to 2015 , the total urban area increased by $90.0 \%$. Urban sprawl intensity of provincial capitals in West China was higher than that in other regions, and East China had the lowest urban sprawl intensity. 2) From year 2000 to 2015, China's provincial capitals tended to be intensive from aspects of GDP per urban area and urban morphology change. 3) From year 2000 to 2015, China's provincial capitals faced the double disharmony between urban sprawl rate and urban population growth rate. Provincial capitals in East China lagged behind urban population growth rate generally. Provincial capitals in Northeast China and Central China were ahead of urban population growth rate generally. 4) From year 2000 to 2015, cultivated land, which occupied $60.6 \%$ of the total urban sprawl areas of China's provincial capitals, was the major source of urban sprawl areas. Construction land, which occupied $27.1 \%$ of the total urban sprawl area, was the second major source of urban sprawl areas.

The future work will include: 1) the optimization of the algorithms, and the transform of manual interpretation rules into machine learning algorithm to improve the efficiency of urban boundary extraction; 2) the application of the high precision urban boundary product of China's provincial capitals to government and public by integrating thematic data.

\section{ACKNOWLEDGEMENTS}

This research is supported by National Key R\&D Program of China (No. 2016YFE0205300), National Natural Science Foundation of China (No. 41401513), and Fundamental Research Fund for the Central Public-interest Scientific Institution (No. 7771803).

\section{REFERENCES}

Angiuli, E., Trianni, G., 2013. Urban mapping in landsat images based on normalized difference spectral vector. IEEE Geoscience \& Remote Sensing Letters, 11(3), pp. 661-665.

Bagan, H., Yamagata, Y., 2012. Landsat analysis of urban growth: How tokyo became the world's largest megacity during the last 40 years. Remote Sensing of Environment, 127, pp. 210-222.
Bagan H, Y.Y., 2012. Landsat analysis of urban growth: How tokyo became the world's largest megacity during the last 40 years. Remote Sensing of Environment, 127, pp. 210-222. Bank, W., 2015. East asia's changing urban landscape.

Bartholome, E.M., Belward, A.S., 2005. Glc2000: A new approach to global land cover mapping from earth observation data. International Journal of Remote Sensing, 26(9), pp. 1959-1977.

Boyce, R.R., Clark, W.A.V., 1964. The concept of shape in geography. Geographical Review, 54(4), pp. 561-572.

Chao, T., Tan, Y., Cai, H., Bo, D.U., Tian, J., 2010. Objectoriented method of hierarchical urban building extraction from high-resolution remote-sensing imagery. Acta Geodaetica Et Cartographica Sinica, 39(1), pp. 39-45.

Che, Q., Duan, X., Yao, G., Lei, W., Cao, Y., 2011. Urban spatial expansion process, pattern and mechanism in yangtze river delta. Acta Geographica Sinica, 66(4), pp. 446-456.

Chen, H., Tao, C., Zou, Z., Yu, F., 2013. Automatic urban area extraction using a gabor filter and high-resolution remote sensing imagery. Geomatics and Information Science of Wuhan University, 38(9), pp. 1063-1067.

Costa, J.N.D., Bielecka, E., Calka, B., Costa, J.N.D., Bielecka, E., Calka, B., Costa, J.N.D., Bielecka, E., Calka, B., 2016. Uncertainty quantification of the global rural-urban mapping project over polish census data, Environmental Engineering.

Duan, D., Huang, B., 2008. Differentiation and analysis of the concept of central city region. Modern Urban Research, 23(10), pp. 20-24.

Friedl, M.A., Mciver, D.K., Hodges, J.C.F., Zhang, X.Y., Muchoney, D., Strahler, A.H., Woodcock, C.E., Gopal, S., Schneider, A., Cooper, A., 2002. Global land cover mapping from modis: Algorithms and early results. Remote Sensing of Environment, 83(1-2), pp. 287-302.

Gao, F., De Colstoun, E.B., Ma, R., Weng, Q., Masek, J., Chen, J., Pan, Y., Song, C., 2012. Mapping impervious surface expansion using medium-resolution satellite image time series: A case study in the yangtze river delta, Cchina. International Journal of Remote Sensing, 33(24), pp. 76097628.

Gong, P., Howarth, P.J., 1992a. Frequency-based contextual classification and gray-level vector reduction for land-use identification. Photogrammetric Engineering \& Remote Sensing, 58, pp. 423-437.

Gong, P., Howarth, P.J., 1992b. Land-use classification of spot hrv data using a cover-frequency method. International Journal of Remote Sensing, 13(8), pp. 1459-1471.

Griffiths, P., Hostert, P., 2010. Mapping megacity growth with multi-sensor data. Remote sens environ. Remote Sensing of Environment, 114(2), pp. 426-439.

Guindon, B., Zhang, Y., Dillabaugh, C., 2004. Landsat urban mapping based on a combined spectral-spatial methodology. Remote Sensing of Environment, 92(2), pp. 218-232. 
Hu, D.Y., Li, J., Chen, Y., Zhang, B., Peng, G., 2006. An analysis of urban expansion and its dynamics based on multitemporal landsat data. Remote Sensing for Land \& Resources, 2006(6), pp. 46-49.

Huang, H., Yun, Y., 2012. Urban expansion in the core area of tianjin based rs and gis. Journal of Arid Land Resources \& Environment, 26(7), pp. 165-171.

Li, M., Zang, S., Wu, C., Tian, Y., 2017. Spatial and temporal variation and its driving forces of urban impervious surface in urban-rural continuum of harbin. Acta Geographica Sinica, 28(3), pp. 323-336.

Li, X., Gong, P., Liang, L., 2015. A 30-year (1984-2013) record of annual urban dynamics of beijing city derived from landsat data. Remote Sensing of Environment, 166(1), pp. 7890 .

Li, X., Wen, J., Lin, J., 2012. Review of research on land urbanization and related studies. Progress in Geography, 31(8), pp. 1042-1049.

Lin, X., Ning, X., 2017. Extraction of human settlements from high resolution remote sensing imagery by fusing features of right angle corners and right angle sides. Acta Geodaetica Et Cartographica Sinica, 46(1), pp. 83-89.

Mu, F.Y., Zhang, Z.X., Chi, Y.B., Liu, B., Zhou, Q.B., Wang, C.Y., Tan, W.B., 2007. Dynamic monitoring of built-up area in beijing during 1973-2005 based on multi-original remote sensed images. Journal of Remote Sensing, 11(2), pp. 257-268.

Ni, H., Lin, X., Ning, X., 2017. A method for extracting human settlements from remote sensing image using right angle corners features. Wuhan Daxue Xuebao, 42(5), pp. 648655 .

Ning, X., Lin, X., 2017. An index based on joint density of corners and line segments for built-up area detection from high resolution satellite imagery. ISPRS International Journal of Geo-Information, 6(11), pp. 338.

P.R.C, M.o.H.a.U.-R.D.o., 1999. Standard for a basic terminology of urban planning. China Architecture \& Building Press 47-49 pp.

Schneider, A., Friedl, M.A., Potere, D., 2010. Mapping global urban areas using modis 500-m data: New methods and datasets based on 'urban ecoregions'. Remote Sensing of Environment, 114(8), pp. 1733-1746.

Schneider, A., Woodcock, C.E., 2008. Compact, dispersed, fragmented, extensive? A comparison of urban growth in twenty-five global cities using remotely sensed data, pattern metrics and census information. Urban Studies, 45(3), pp. 659.
Son, N.T., Chen, C.R., 2012. Urban growth mapping from landsat data using linear mixture model in ho chi minh city, vietnam. Journal of Applied Remote Sensing, 6(1), pp. 100106.

Stone, B., Hess, J.J., Frumkin, H., 2010. Urban form and extreme heat events: Are sprawling cities more vulnerable to climate change than compact cities? Environmental Health Perspectives, 118(10), pp. 1425-1428.

Sun, Z., Wang, C., Guo, H., Shang, R., 2017. A modified normalized difference impervious surface index (mndisi) for automatic urban mapping from landsat imagery. Remote Sensing, 9(9), pp. 942.

Tan, M., Li, X., Xie, H., Lu, C., 2005. Urban land expansion and arable land loss in china- a case study of beijing-tianjinhebei region. Land Use Policy, 22(3), pp. 187-196.

Wan, B., Guo, Q., Fang, F., Su, Y., Wang, R., 2015. Mapping us urban extents from modis data using one-class classification method. Remote Sensing, 7(8), pp. 10143-10163.

Wang, F., Liu, Y., 2013. Panel granger test on urban land expansion and fiscal revenue growth in china's prefecturelevel cities. Acta Geographica Sinica, 68(12), pp. 1595-1606.

Wang, L., LI, C.C., Ying, Q., Cheng, X., Wang, X., 2012. China's urban expansion from 1990 to 2010 determined with satellite remote sensing. Science Bulletin, 57(22), pp. 28022812.

Weicheng, X., 2002. Encyolopedia of china. Encyclopedia of China Publishing House, Beijing.

Xu, Z., Gao, X., 2016. A novel method for identifying the boundary of urban built-up areas with poi data. Acta Geographica Sinica, 71(6), pp. 928-939.

Yin, Z.Y., Walcott, S., Kaplan, B., Cao, J., Lin, W., Chen, M., Liu, D., Ning, Y., 2005. An analysis of the relationship between spatial patterns of water quality and urban development in shanghai, china. Computers Environment \& Urban Systems, 29(2), pp. 197-221.

Yuan, F., Bauer, M.E., 2007. Comparison of impervious surface area and normalized difference vegetation index as indicators of surface urban heat island effects in landsat imagery. Remote Sensing of Environment, 106(3), pp. 375-386.

Zhang, T., Wang, Y., Liu, Y., Peng, J., 2016. Multi-temporal detection of landscape evolution in western shenzhen city during 1987-2015. Acta Geographica Sinica, 71(12), pp. 2170-2184. 